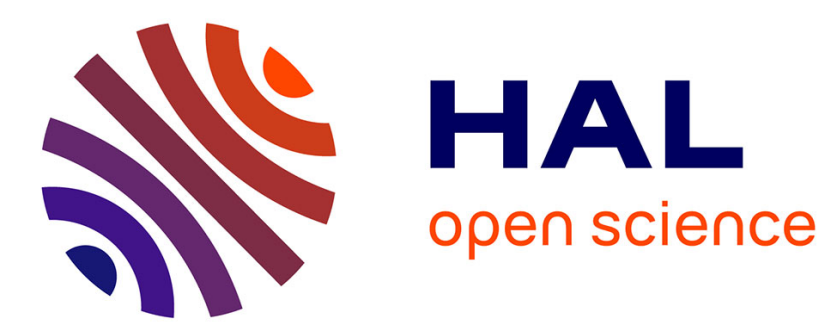

\title{
The mechanism for the stabilization and surfactant properties of epitaxial silicene
}

\author{
A. Curcella, R. Bernard, Y. Borensztein, M. Lazzeri, G. Prévôt
}

\section{To cite this version:}

A. Curcella, R. Bernard, Y. Borensztein, M. Lazzeri, G. Prévôt. The mechanism for the stabilization and surfactant properties of epitaxial silicene. Nanoscale, 2018, 10 (5), pp.2291-2300. 10.1039/C7NR06833F . hal-01701778

\section{HAL Id: hal-01701778 \\ https://hal.sorbonne-universite.fr/hal-01701778}

Submitted on 6 Feb 2018

HAL is a multi-disciplinary open access archive for the deposit and dissemination of scientific research documents, whether they are published or not. The documents may come from teaching and research institutions in France or abroad, or from public or private research centers.
L'archive ouverte pluridisciplinaire HAL, est destinée au dépôt et à la diffusion de documents scientifiques de niveau recherche, publiés ou non, émanant des établissements d'enseignement et de recherche français ou étrangers, des laboratoires publics ou privés. 


\title{
Mechanism for the stabilization and surfactant properties of epitaxial silicene
}

\author{
A. Curcella, ${ }^{a}$ R. Bernard, ${ }^{a}$ Y. Borensztein, ${ }^{a}$ M. Lazzeri, ${ }^{b}$ G. Prévot ${ }^{c}$
}

Using real-time in-situ scanning tunneling microscopy and density functional theory simulations, we have studied the growth of Si films on Ag(111) beyond the silicene monolayer, evidencing the existence of metastable phases and an original growth mechanism. Above monolayer Si coverage, a first $(\sqrt{3} \times \sqrt{3}) R 30^{\circ}$ structure forms, which is identified as an Ag-free Si bilayer with additional Si adatoms. With further deposition, this structure is replaced by a distinct bilayer structure covered by Si trimers and Ag atoms. The formation of these bilayers follows a counterintuitive dynamics: they are partially inserted within the Ag substrate and form by expelling, from the underlying substrate, atoms that reinsert below the adjacent silicene layer. The growth is therefore characterized by an unexpected "surfactant competition" between $\mathrm{Ag}$ and silicene: while silicene is a metastable surfactant for the $\mathrm{Ag}(111)$ surface, Ag plays the role of a surfactant for thicker diamond-like Si islands. In spite of being thermodynamically unfavoured, the silicene monolayer is, thus, a remarkably stable structure because of the high kinetic-barrier for the growth of thicker layers.

\section{Introduction}

Two-dimensional atomic layers, like graphene, silicene, germanene or phosphorene, metal dichalcogenides or trichalcogenides, or boron nitrides, show an increasing interest due to their specific and promising properties. ${ }^{1,2}$ Whereas graphene, phosphorene and chalcogenides can be obtained by exfoliation of the bulk material, this is not the case for silicene, since no graphite analogue exists for silicon. However, since the first theoretical predictions of the existence of metastable free-standing silicene, ${ }^{3-5}$ many efforts have been devoted to the synthesis of epitaxial silicene. ${ }^{6-11}$ Epitaxial Si monolayers have been first synthesized on Ag substrates: Si dimers have been observed on $\mathrm{Ag}(100),{ }^{12}$ Si nanoribbons on $\mathrm{Ag}(110),{ }^{13}$ with a pentagonal organization recently determined, ${ }^{14,15}$ whereas formation of a silicene layer was evidenced on $\mathrm{Ag}(111) .{ }^{16}$ On this surface, various ordered structures have been found to coexist, with a relative proportion depending on the preparation conditions. ${ }^{17-19}$ They all display a buckled hexagonal organization, with a buckling related to the matching between the Si and $\mathrm{Ag}$ lattices. ${ }^{20}$

The silicene structures that form on $\mathrm{Ag}(111)$ are however metastable. During growth at temperatures higher than $540 \mathrm{~K}$, the silicene layer dewets before its completion, leading to the formation of large three dimensional (3D) silicon islands separated by bare $\mathrm{Ag}$ regions. ${ }^{21} \mathrm{~A}$ similar result is observed after annealing, at $600 \mathrm{~K}$, of a silicene layer grown at lower temperature. $^{21,22}$ However, if growth is performed at temperatures lower than $540 \mathrm{~K}$, a pseudo layer-by-layer growth mode (Frank van der Merwe) ${ }^{23-27}$ is observed, leading to the formation of thin silicon films terminated by a $(\sqrt{3} \times \sqrt{3}) R 30^{\circ}$ reconstruction. This reconstruction is observed after completion of the first monolayer, and corresponds thus to a thicker layer. ${ }^{25,26,28}$ On the basis of $X$ ray diffraction and Raman spectroscopy, such films have been described as a new class of material, silicite, the equivalent of graphite for silicon atoms, also called multilayer silicene. ${ }^{29-31}$ Following these observations, various atomic models have been proposed, based on density functional theory (DFT) calculations, as alternatives to the classical diamond structure of $\mathrm{Si}$, for bilayers or multilayer films. ${ }^{32-40}$ However, these results have been questioned by further independent experimental studies, concluding that the multilayer Si films structure is similar to the diamond-like structure of bulk $\mathrm{Si}$, and that $\mathrm{Ag}$ atoms segregates at the surface during growth. ${ }^{41-45}$

The exact termination of the surface remains also debated. Reconstructions involving only silicon atoms have been suggested on the basis of experimental and simulation results. ${ }^{46-49}$ However, the presence of $\mathrm{Ag}$ atoms on top of the surface has been confirmed by spectroscopic and microscopic measurements, ${ }^{50-52}$ proposing that the observed $(\sqrt{3} \times \sqrt{3}) R 30^{\circ}$ reconstruction is similar to the well known $\mathrm{Ag} / \mathrm{Si}(111)$ reconstruction. ${ }^{53,54}$ In any case, $\mathrm{Si}$ islands covered by $\mathrm{Ag}$ atoms are recognised as the most stable configuration. $^{30,31}$

Open questions remain on the nature of the bulk and surface structure of the silicon films that can be grown at moderate temperature $(470 \mathrm{~K}-500 \mathrm{~K})$. In particular, is it possible to grow metastable multilayer silicene structures? On the contrary, how does the surface evolve from a single silicene layer to a thick Si film covered with Ag? Most important, silicene, which is not stable with respect to bulk diamond, is commonly observed, in standard growth conditions, even in the presence of bulk nucleation centers. Why is silicene so unusually stable? Silicene/ $\mathrm{Ag}(111)$ is a paradigmatic case of a $2 \mathrm{D}$ material which cannot be obtained by exfoliation from bulk material. Understanding these specific points is, thus, a step towards a more general goal: the synthesis of new phases, potentially thermodynamically unfavoured, keeping a weak interaction with the substrate.

To answer these questions, we have used real-time in-situ STM and DFT calculations to study the growth of Si films on $\mathrm{Ag}(111)$ in the $470-500 \mathrm{~K}$ temperature range. We have evidenced the existence of metastable phases and an original growth mechanism, which is schematized in Figure 1. In spite of being thermodynamically unfavoured, the silicene monolayer is a relatively stable structure with respect to atom addition. Above one monolayer Si coverage (Figure 1a), a first $(\sqrt{3} \times \sqrt{3}) R 30^{\circ}$ structure forms which is identified as an Agfree bilayer with additional Si atoms (Figure 1b). With further Si deposition, this structure is replaced by a slightly thicker one, covered by Si trimers and $\mathrm{Ag}$ atoms (Figure 1c). The formation of these $\mathrm{Si}$ bilayers follows a counterintuitive dynamics: the bottom layer is located below the original silicene monolayer and forms by dislodging the atoms of the outermost Ag layer. These Ag atoms either wet the bilayer, or 
intercalate between the substrate and the remaining silicene monolayer. The growth is thus associated with a high kinetic barrier which further enhances the stability of the silicene monolayer which behaves as a surfactant.

\section{Results}

The mechanism of growth of the silicene monolayer on $\mathrm{Ag}(111)$ has been recently described. ${ }^{55-57}$ At $500 \mathrm{~K}, \mathrm{Si}$ atoms first insert in the Ag surface plane and act as nucleation centers for the growth of large silicene domains with mainly $(4 \times 4)$ and $(\sqrt{13} \times \sqrt{13})$ reconstructions (these periodicities refer to the $\mathrm{Ag}$ surface, and correspond to $(3 \times 3)$ and $(\sqrt{7} \times \sqrt{7})$ reconstructions, respectively, when referred to the pristine silicene plane). Ag atoms are expelled and form new terraces that are further covered with silicon. For coverage larger than nearly one monolayer $\left(1 \mathrm{ML}=1.5610^{15} \mathrm{at} / \mathrm{cm}^{2}\right)$, the growth is characterized by the development of $(4 / \sqrt{3} \times 4 / \sqrt{3})$ reconstructed islands, commonly referred to as $(\sqrt{3} \times \sqrt{3})$ (with respect to the pristine silicene plane). Such islands cover relatively smaller areas with respect to the silicene monolayer. Sone et al. ${ }^{26}$ have actually shown that two kinds of islands are observed: $(\sqrt{3} \times \sqrt{3})-\alpha$ and $(\sqrt{3} \times \sqrt{3})-\beta$, the latter ones progressively increasing at the expense of the former ones with further Si deposition.

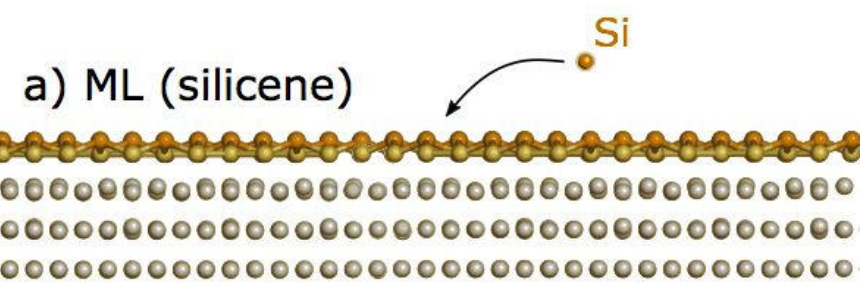

b) $\mathrm{BL}+\mathrm{Si}$

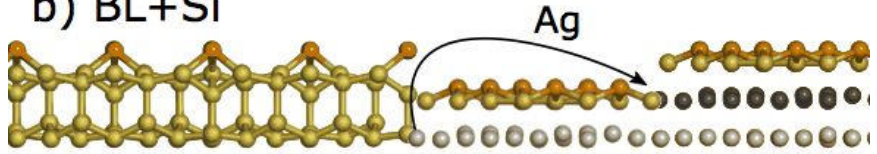

000000000000000000000000000000000001 1000000000000000000000000000000000001

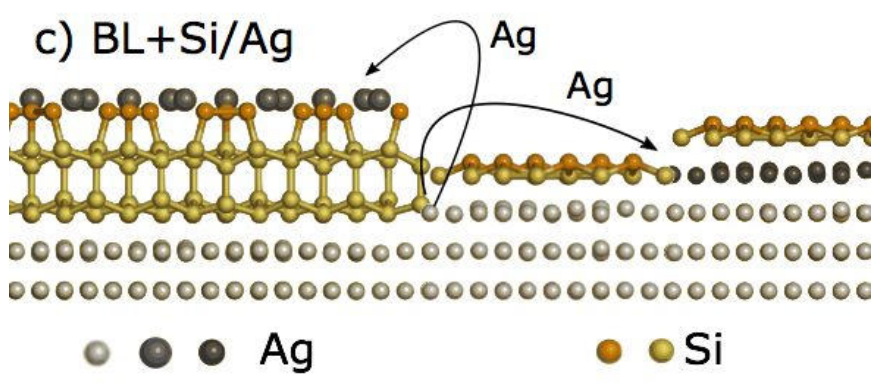

Figure 1: a) initial silicene monolayer (ML); b) formation of the Ag-free bilayer (BL+Si); c) the initial bilayer is replaced with a different $\mathrm{Ag}$-rich reconstruction $(\mathrm{BL}+\mathrm{Si} / \mathrm{Ag}$ ). Note that in b) and c) the bilayer is inserted within the substrate, leading to the expulsion of $\mathrm{Ag}$ atoms that either reinsert below the silicene layer or adsorb above the growing bilayer.

STM measurements: $(\sqrt{3} \times \sqrt{\mathbf{3}})-\alpha$ and $(\sqrt{\mathbf{3}} \times \sqrt{\mathbf{3}})-\beta$ islands.

In Figure 2 (present measurements), the $(\sqrt{3} \times \sqrt{3})-\alpha$ and $\beta$ islands are visible, surrounded by different phases of silicene (1 ML) with $(4 \times 4)$ (lower right) and $(\sqrt{13} \times \sqrt{13})$ (upper left) reconstructions. The measured size of the unit cell is $0.66 \pm 0.03$ $\mathrm{nm}$. The $\alpha$ and $\beta$ islands do not display the same surface appearance. First, their contrast is inverted: while the $(\sqrt{3} \times \sqrt{3})$ triangular pattern of the $\alpha$ islands corresponds to outward protrusions, the $\beta$ one corresponds to intrusions. Second, their corrugations are different, being $\sim 0.06 \mathrm{~nm}$ for the $\alpha$ islands and $\sim 0.02 \mathrm{~nm}$ for the $\beta$ ones (Figure 2b). This corrugation difference suggests an hypothetically more metallic character of the $\beta$ islands. Finally, contrary to previous observations, ${ }^{26}$ the apparent heights of the islands are markedly different: while the $\alpha$ islands are observed at $0.21 \pm 0.01 \mathrm{~nm}$ above the surrounding silicene monolayer (Figure 2), the $\beta$ ones are at $0.31 \pm 0.01 \mathrm{~nm}$. Thus, without making assumptions on the exact structure of the $\alpha$ and $\beta$ islands, Figure 2 clearly indicates that their atomic and electronic structures are different. 

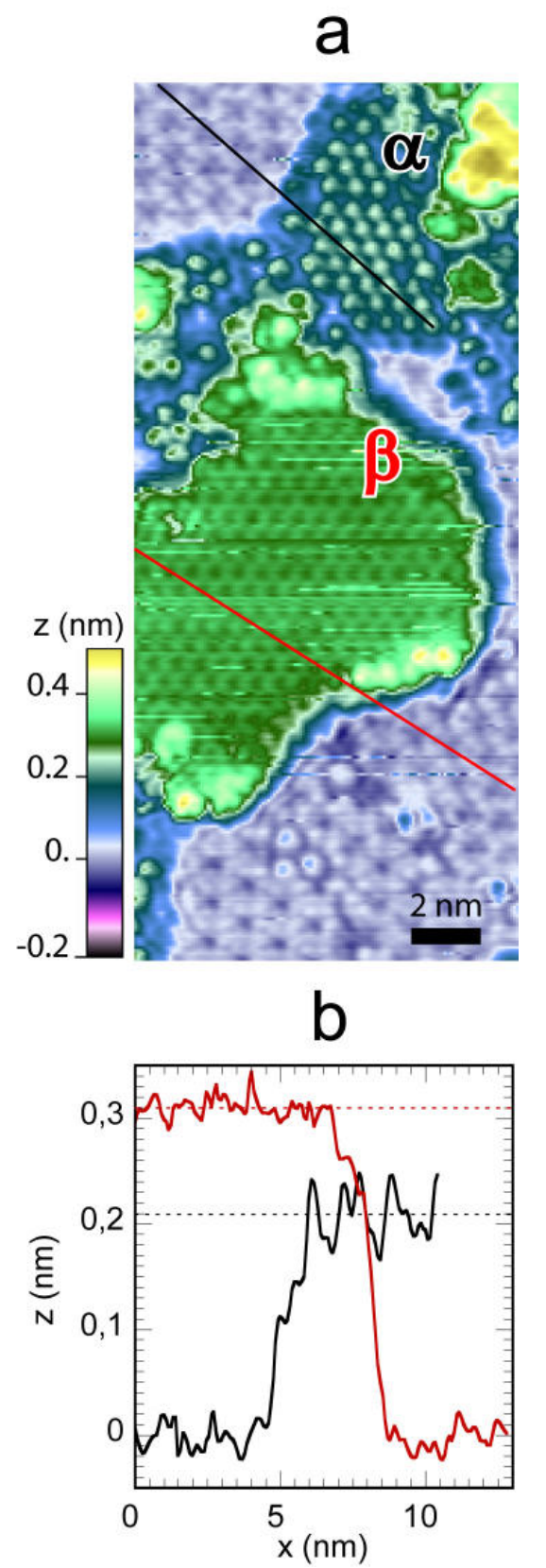

Figure 2: (a) STM image after Si evaporation at $500 \mathrm{~K}$ above 1 silicene monolayer. The $(\sqrt{3} \times \sqrt{3})-\alpha$ and $(\sqrt{3} \times \sqrt{3})-\beta$ islands display a different STM contrast. (b) profiles along the lines shown in (a). Size of the image: $11 \times 25 \mathrm{~nm}^{2}$. Tunneling conditions: $U=1.6 \mathrm{~V}-I=50 \mathrm{pA}$.

\section{Evolution of the $(\sqrt{3} \times \sqrt{3})$ islands with increasing $\mathrm{Si}$ deposition}

Figure 3 displays the evolution of the same region during $\mathrm{Si}$ growth above the silicene monolayer at $500 \mathrm{~K}$. The set of images correspond to detailed views of a $700 \times 700 \mathrm{~nm}^{2}$ area that is also periodically fully scanned with a lower resolution. The regions labeled $S_{-1}$ (magenta), $S$ (lavender), $S_{1}$ (seafoam/light-green), and $\mathrm{S}_{2}$ (light-yellow) correspond to silicene monolayers lying on different $\mathrm{Ag}$ terraces. All these regions are staggered in height by multiples of $0.235 \mathrm{~nm}$ which is the height of a $\mathrm{Ag}(111)$ step. Within each of these regions, the monolayer displays domains with different reconstructions, mainly $(4 \times 4)$ and $(\sqrt{13} \times \sqrt{13})$. The darker dotted lines are defects present at the boundaries between the domains. After completion of the first Si layer, islands with $(\sqrt{3} \times \sqrt{3})-\alpha$ reconstruction are growing. They correspond, for example, to the small green islands visible in Figure 3a (labeled " $\alpha$ "). For larger amounts of silicon, they are progressively replaced by the $(\sqrt{3} \times \sqrt{3})-\beta$ islands (green areas in Figure $3 c$, labeled " $\beta$ ", then brown and red areas in Figure $3 c-e)$. This evolution can be seen more easily in the zoom reported in Figure 4.

In Figure 4, the different domains of silicene monolayer (lavender area) are clearly visible. Two islands at a higher level can also be seen. In Figure $4 a$, the bottom-left one partly consists of $(\sqrt{3} \times \sqrt{3})-\alpha \quad$ (turquoise), where the reconstruction is visible, and partly of $(\sqrt{3} \times \sqrt{3})-\beta$ (green), which is not resolved as in Figure $2 \mathrm{a}$ because of the different tunneling conditions. For a larger amount of deposited Si (Figure $4 \mathrm{~b}$ ), the $\alpha$ domain of the lower island is completely replaced by the $\beta$ structure. Upon further Si evaporation, the $\beta$ domains continue growing laterally while the $\alpha$ ones progressively disappear, as it is visible in Figure $3 \mathrm{~b}$ and $\mathrm{c}$. Eventually, only silicene areas and $\beta$ islands are present. $\beta$ islands also grow vertically in a layer-by-layer way. In Figure 3, $\beta$ (green), $\gamma$ (brown), and $\delta$ (red) correspond to areas of increasing heights with the same apparent topographical contrast. The interlayer spacing, $0.30 \pm 0.01 \mathrm{~nm}$, is similar to what observed by others ${ }^{25,42,52}$ and could correspond to the distance between two silicene layers as well as to the height of a (111) step of bulk Si.

\section{Intercalation of Ag layers under the silicene single layer}

In addition to this classical layer-by-layer growth of the $\beta$ islands, the evolution of the silicene regions displays a much unexpected behavior. Surprisingly, the comparison of Figures 3a-f shows that the height of the silicene monolayer increases during Si evaporation. For example, the region on the left of the cross is $0.235 \mathrm{~nm}$ higher on Figure 3e-f $\left(\mathrm{S}_{1}\right.$, seafoam) than in Figure 3a-d (S, lavender). Other examples are the $\mathrm{S}_{-1}$ region (magenta, on the left part of Figures $3 a, b, c)$, which progressively disappears at the expense of the $S$ one (lavender), and the $S_{2}$ region visible in the top-right position in Figures $3 c, d$, which laterally grows at the expense of the $S_{1}$ (seafoam) one.

In order to better explain these evolutions, Figure 5 reports STM scanning at a finer scale. It must be noticed that the amounts of deposited $\mathrm{Si}$ in Figure 5 do not exactly correspond to the ones in Figure 3, as Si was continuously deposited during the scanning of the STM. On the left side of Figure 5a, two parts of a $\beta$ island (coloured in green) are present. They are identified by their surface appearance and by their height $\left(h_{\mathrm{Si} \beta}=0.32 \pm 0.01 \mathrm{~nm}\right.$ ) with respect to the silicene layer $(\mathrm{S})$ as it is shown by the profile along the red line, Figure $5 \mathrm{~d}$. With increasing amount of deposited $\mathrm{Si}$, several modifications can be observed in Figure $5 b$, then in Figure $5 c$ : (i) the $\beta$ island is 


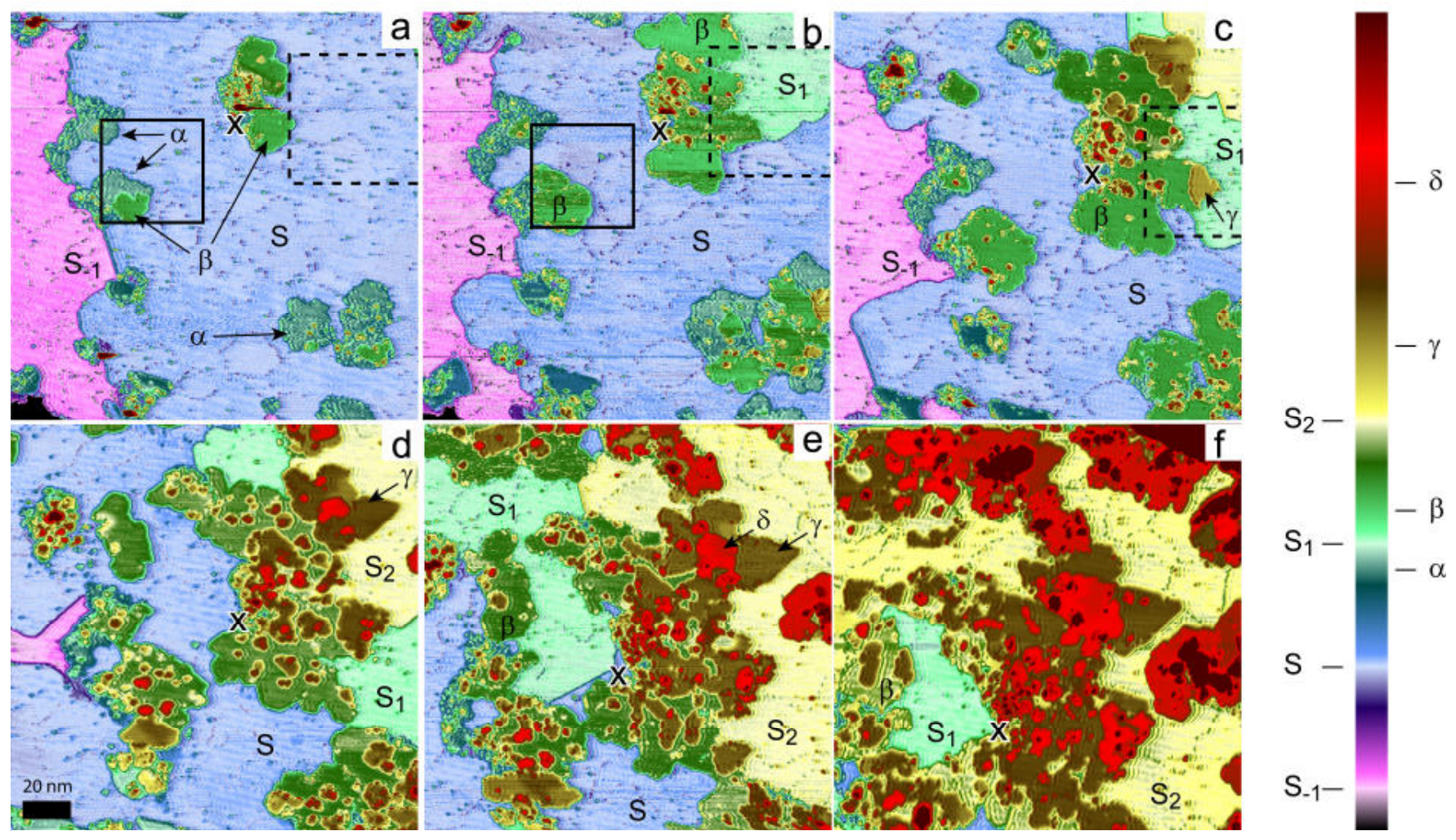

Figure 3: (a-f) STM images of the same area during continuous Si evaporation at $500 \mathrm{~K}$. Image (a) corresponds to a coverage slightly above $1 \mathrm{ML}$. Si coverage increases from panel (a) to (f). The black cross indicates a reference position and the squares correspond to the detailed views in Figures 4 and 5 . The colourscale spans $1.58 \mathrm{~nm}$ range. $\mathrm{S}_{-1}, \mathrm{~S}, \mathrm{~S}_{1} \mathrm{~S}_{2}$ label areas of silicene monolayers lying on different Ag terraces. $\alpha, \beta, \gamma$ and $\delta$ correspond to Si islands of increasing height that have grown on the terrace S. Size of the images: $168 \times 168 \mathrm{~nm}^{2}$. Tunneling conditions: $U=1.8 \mathrm{~V}-I=50 \mathrm{pA}$.

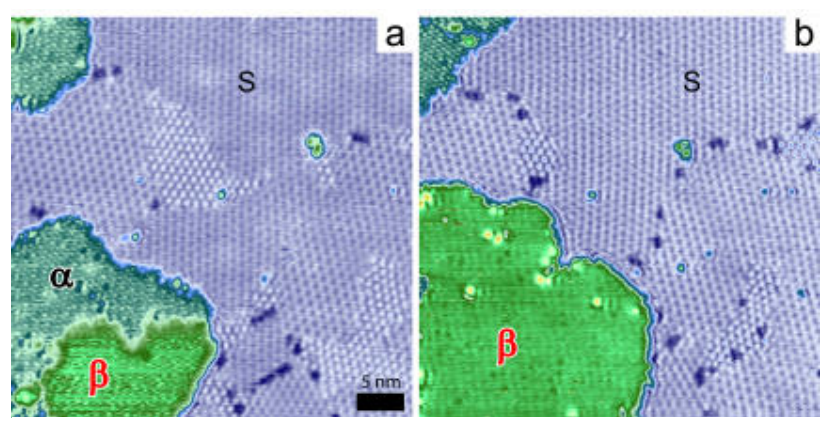

Figure 4: Detailed view of Figures $3 a$ and $3 b(42 \times 42 \mathrm{~nm} 2)$ corresponding to the position of the continuous black squares drawn in Figure 3 .

spreading out on the surface and covers a larger part of the silicene layer (left part of the figures, in green); (ii) the majority of the silicene layer $\left(S_{1}\right.$ in seafoam colour in Figure $\left.5 b, c\right)$ is now $0.235 \pm 0.01 \mathrm{~nm}$ above the initial silicene layer ( $\mathrm{S}$ in lavender colour in Figure $5 \mathrm{a}$ ), as shown by the height profiles along the black line; (iii) a new level of silicene layer is appearing at the upper right part of Figure $5 c\left(S_{2}\right.$, yellow), $0.235 \pm 0.01 \mathrm{~nm}$ above the $\mathrm{S}_{1}$ silicene layer; (iv) a new flat island coloured in brown $(\gamma)$ is developing upon the $\beta$ island coloured in green in Figure $5 c$, corresponding to a height increase $h_{\mathrm{Si}}=0.30 \pm 0.01 \mathrm{~nm}$.

The most striking feature is that the height increase of the silicene regions, when changing from $S$ to $S_{1}$ and from $S_{1}$ to $S_{2}$, coincides with $h_{\mathrm{Ag}}=0.235 \mathrm{~nm}$, which is the height of a single $\mathrm{Ag}(111)$ step. It is also very remarkable that the different domains and their orientations observed on the initial silicene layer (S region, lavender in Figure $5 a$ ) are generally preserved

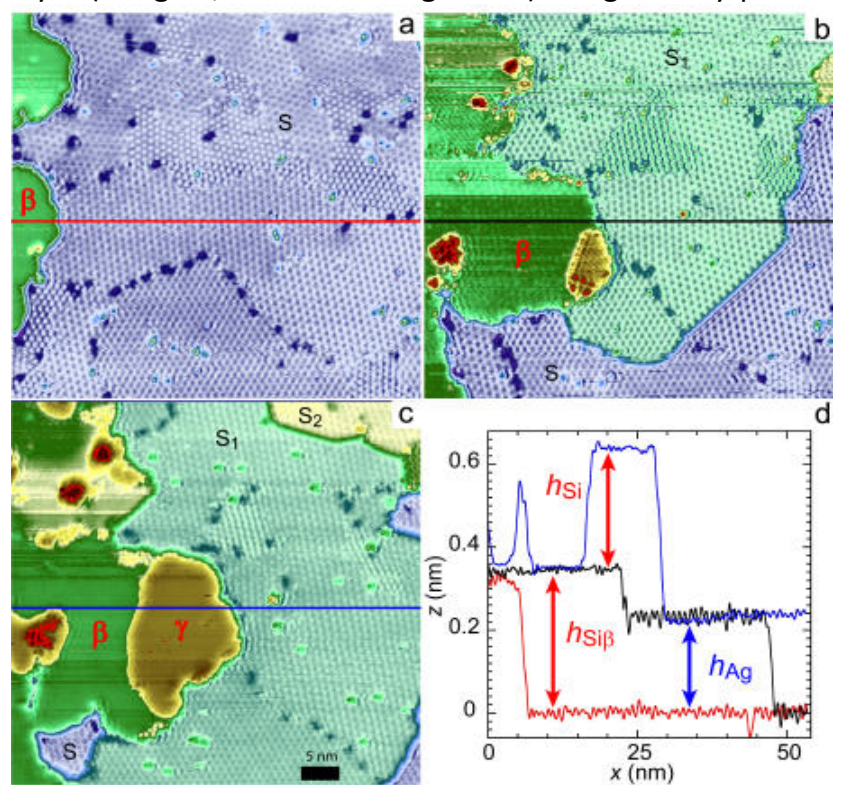

Figure 5: (a-c) Detailed view of the evolution of the silicene layer during Si evaporation at $500 \mathrm{~K}$ corresponding to the dotted squares drawn in Figure 3 . The region is exactly the same for images a-c. Size of the images $53 \times 52 \mathrm{~nm}^{2}$. d) Evolution of the STM height profile: the red, black, and blue profiles correspond to the horizontal lines drawn in panel $a, b$, and c, respectively.

in the corresponding higher silicene terrace $\left(S_{1}\right.$, seafoam in Figure $5 b)$. This is clearly seen in the bottom of Figure $5 b$ where the growth front separates upper $\left(\mathrm{S}_{1}\right)$ and lower terraces $(S)$ with the same $(4 \times 4)$ reconstruction. These 
observations indicate that the growth (from $S$ to $S_{1}$ and from $S_{1}$ to $S_{2}$ ) corresponds to the insertion of an additional Ag layer (located at $h_{\mathrm{Ag}}$ above the initial (111) Ag surface) below the silicene layer and not to a second silicene layer which would grow above the first one at $h_{\mathrm{Si}} \approx \frac{4}{3} h_{\mathrm{Ag}}$. This is the signature of an unexpected intercalation of an $\mathrm{Ag}$ layer below the silicene layer, which, in turn, preserves its structure during the process.

\section{DFT Calculations: structures and simulation of STM topography}

The structure and energetics of various $\mathrm{Si} / \mathrm{Ag}$ multilayers were calculated within DFT. Shown results are obtained with the generalized gradient approximation (GGA), ${ }^{58}$ which gives the best agreement with $X$ ray diffraction measurements for the structure of $(4 \times 4)$ silicene. ${ }^{20}$ Results were tested against the inclusion of dispersive corrections as in refs. 59-60. Unless otherwise stated, we consider silicene-based super-cells with $(3 \times 3)$ periodicity lying on a $(4 \times 4) \mathrm{Ag}(111)$ surface super-cell. In order to determine the nature of the $(\sqrt{3} \times \sqrt{3})-\alpha$ and $(\sqrt{3} \times \sqrt{3})-\beta$ reconstructions, we tested various possibilities. $A$ first set corresponds to pure silicon structures lying on $\mathrm{Ag}(111)$, labelled "BL-AB", "ML+Si", "BL+Si", and "BL-AA". The "BL-AB" structure is a silicon bilayer with $A B$ stacking; "ML+Si" corresponds to a Si monolayer in which three $\mathrm{Si}$ atoms are added to form the trigonal dumbbell (TDS) structure proposed in ref. 34; "BL+Si" corresponds to an $A B$ bilayer in which three $\mathrm{Si}$ atoms are added, in analogy to the TDS one. In both the $\mathrm{ML}+\mathrm{Si}$ and $\mathrm{BL}+\mathrm{Si}$ structures the outermost three $\mathrm{Si}$ atoms are added on the top of three Si atoms inward buckled forming a $(\sqrt{3} \times \sqrt{3})$ periodicity. This configuration is inspired by the very stable $(7 \times 7)$ reconstruction of the $\mathrm{Si}(111)$ surface. "BL$A A^{\prime \prime}$ is a silicon bilayer with stacking $A A$ as proposed by Pflugradt et al. ${ }^{38}$ (the BL-AA structure has a true periodicity of $(2 \sqrt{3} \times 2 \sqrt{3})$, and lies on a $(\sqrt{19} \times \sqrt{19})$ Ag super-cell). A second set of structures are silicene layers covered by $\mathrm{Si}$ and $\mathrm{Ag}$ atoms arranged in analogy to the reconstruction observed when the $\mathrm{Si}(111)$ surface is covered by $\mathrm{Ag}: \mathrm{Ag} / \mathrm{Si}(111)$ $(\sqrt{3} \times \sqrt{3})$. In this configuration, a silicene monolayer covered by half a silicene layer and nine $\mathrm{Ag}$ atoms per unit cell will be labeled as "ML+Si/Ag". "BL+Si/Ag" labels an analogous structure obtained from a $\mathrm{Si} A B$ bilayer. We recall that the
$\mathrm{Ag} / \mathrm{Si}(111) \quad(\sqrt{3} \times \sqrt{3})$ reconstruction is observed in two different configurations which posses, or not, a mirror symmetry. An inequivalent triangle structure (IET, non symmetric) is observed at temperatures smaller than $150 \mathrm{~K}$, while a honeycomb chained triangle ( $\mathrm{HCT}$, symmetric) appears at $\mathrm{T}>150 \mathrm{~K}^{61}$ In the DFT calculations, starting from an appropriate initial guess, it is possible to obtain symmetric and non-symmetric structures for the $\mathrm{Ag} / \mathrm{Si}(111)(\sqrt{3} \times \sqrt{3})$ and for both the $\mathrm{ML}+\mathrm{Si} / \mathrm{Ag}$ and $\mathrm{BL}+\mathrm{Si} / \mathrm{Ag}$ structures. In the following, we will only consider the symmetric ones, assuming that they are stabilized by temperature. Details of the simulated structures are given in the ESI.

Figure 6 shows the simulated STM images for some of these structures. These images were used to estimate the apparent height $h$, as seen by an STM probe, of the different structures with respect to the $(4 \times 4)$ silicene monolayer, and their corrugation $\Delta h . h$ is the average height probed by an ideal spherical tip with radius $1 \mathrm{~nm}$ touching the constant density surface. $\Delta h$ is the difference between the maximum and the minimum height. These values are given in Table 1. Although these numbers cannot be considered as an absolute determination of the corresponding measured quantities, the relative heights of the different theoretical structures should be more comparable with measurements.

\section{Energetics}

To confront the stabilities, we consider the grand canonical surface energy:

$\gamma\left(\mu_{\mathrm{Si}}, \mu_{\mathrm{Ag}}\right)=\frac{1}{A}\left[E_{\mathrm{Slab}}\left(N_{\mathrm{Si}}, N_{\mathrm{Ag}}\right)-\tilde{E}-N_{\mathrm{Si}} \mu_{\mathrm{Si}}-N_{\mathrm{Ag}} \mu_{\mathrm{Ag}}\right]$

$E_{\text {Slab }}$ is the energy of a slab containing $N_{\mathrm{Si}}$ Si atoms and $N_{\mathrm{Ag}}$ $\mathrm{Ag}$ atoms. The bare Ag surface on the bottom of the slab was kept fixed during relaxation. $A$ is the surface area of the slab, $\mu_{\mathrm{Si}}$ and $\mu_{\mathrm{Ag}}$ are the chemical potentials of Si and $\mathrm{Ag}, \tilde{E} / A$ is the surface energy of the bottom bare Ag surface, which is calculated independently. Figure 7 compares the surface energies of the different structures calculated for $\mu_{\mathrm{Ag}}=$ $E_{\mathrm{Ag}}^{\text {bulk }}$, the $\mathrm{Ag}$ cohesive energy in the fcc $\mathrm{Ag}$ lattice. The energies are plotted as a function of $\Delta \mu_{\mathrm{Si}}=\mu_{\mathrm{Si}}-E_{\mathrm{Si}}^{\text {bulk}}$, where $E_{\mathrm{Si}}^{\mathrm{bulk}}$ is the Si cohesive energy in the diamond Si lattice.

\begin{tabular}{|c|c|c|c|c|c|c|c|c|c|}
\hline & ML & ML & $\alpha$ & $\mathrm{BL}+\mathrm{Si}$ & $\mathrm{ML}+\mathrm{Si}$ & $B L-A A$ & $\beta$ & $\mathrm{BL}+\mathrm{Si} / \mathrm{Ag}$ & $\mathrm{ML}+\mathrm{Si} / \mathrm{Ag}$ \\
\hline$h(\mathrm{~nm})$ & 0 & 0 & 0.21 & $\begin{array}{l}0.22 \\
(0.46)\end{array}$ & 0.11 & $\begin{array}{l}0.15 \\
(0.39)\end{array}$ & 0.32 & $\begin{array}{l}0.30 \\
(0.53)\end{array}$ & 0.25 \\
\hline$\Delta h(\mathrm{~nm})$ & 0.05 & 0.08 & 0.06 & 0.09 & 0.08 & 0.08 & 0.02 & 0.05 & 0.04 \\
\hline
\end{tabular}

Table 1: Characteristics of the simulated STM images of the structures described in the text. $h$ is the apparent height with respect to the silicene monolayer and $\Delta h$ is the corrugation (see the text). The quantities in boldface are from measurements. $\alpha$ and $\beta$ refer to the two $(\sqrt{3} \times \sqrt{3})$ phases; ML to the monolayer ( $4 \times 4)$ reconstruction. For the structures containing a Si bilayer, $h$ has been reduced by $0.235 \mathrm{~nm}$ (the Ag-Ag interlayer distance) assuming that the atoms of the outermost Ag layer are expelled during the growth (this choice is clarified in the discussion). The values in parenthesis are obtained without applying this correction. 


\section{A \begin{tabular}{rrrrr}
2.94 & 2.38 & 1.82 & 1.26 & 0.7 \\
\cline { 2 - 4 } & & &
\end{tabular}}
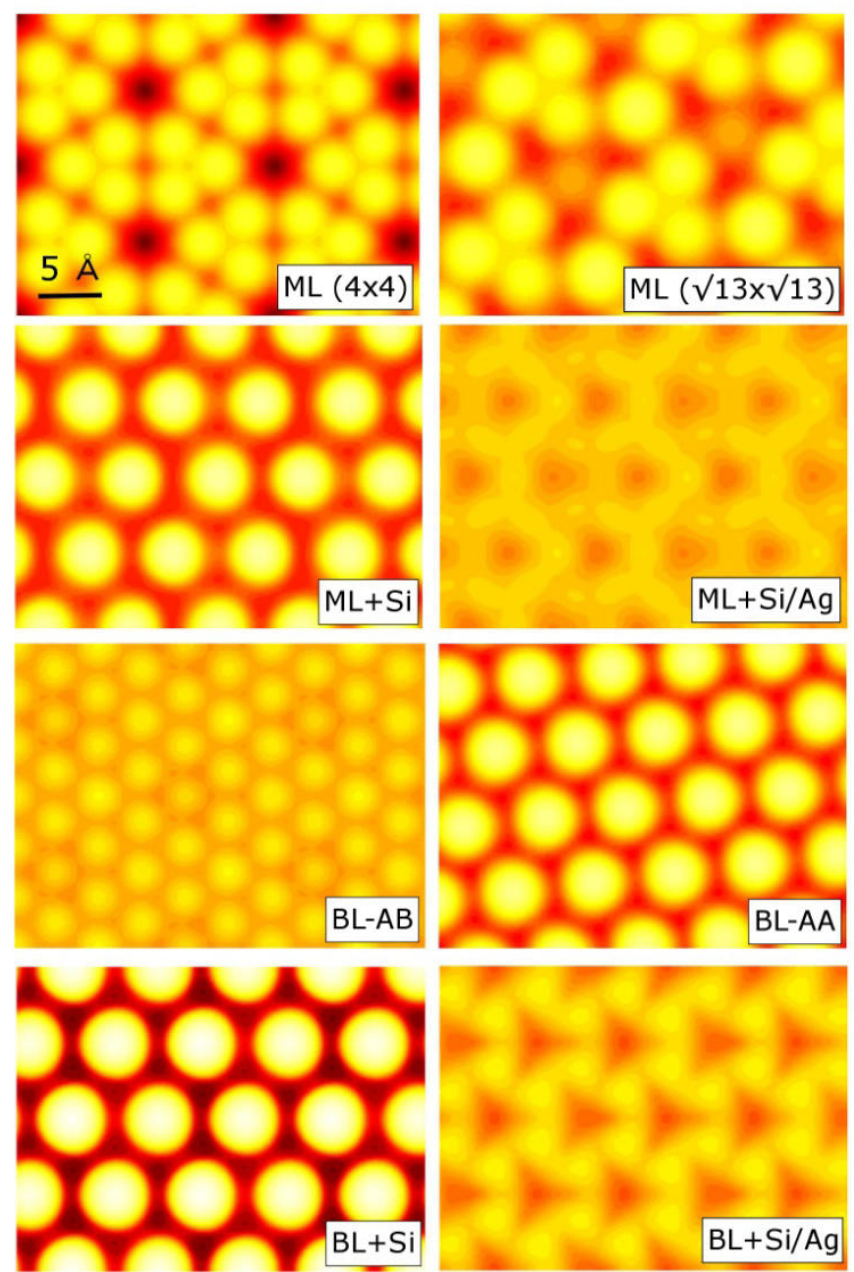

Figure 6: Simulated STM images for the $\mathrm{Si} / \mathrm{Ag}(111)$ thin layers described in the text. STM simulations are done at $U=0.5 \mathrm{~V}$. All the panel correspond to the same cell with the same orientation. $\mathrm{ML}+\mathrm{Si}, \mathrm{ML}+\mathrm{Si} / \mathrm{Ag}, \mathrm{BL}-\mathrm{AA}, \mathrm{BL}+\mathrm{Si}$, and $\mathrm{BL}+\mathrm{Si} / \mathrm{Ag}$ display a $(\sqrt{3} \times \sqrt{3})$ reconstruction with respect to the silicene unit cell. In the $M L+S i, B L-A A$, and $B L+S i$ cases, the $(\sqrt{3} \times \sqrt{3})$ reconstruction consists of an array of bright areas (outward protrusions) and, thus, could correspond to the $\alpha$ phase in Figure 2 . In the $\mathrm{ML}+\mathrm{Si} / \mathrm{Ag}$ and $\mathrm{BL}+\mathrm{Si} / \mathrm{Ag}$ cases, the $(\sqrt{3} \times \sqrt{3})$ reconstruction consists of an array of dark areas (inward intrusions) and, thus, could correspond to the $\beta$ phase in Figure 2.

To further elucidate the growth dynamics, we also calculated the adsorption energy of one single Si atom on various sites on the silicene/ $\mathrm{Ag}(111)$ structure. Results are reported in the Electronic Supplementary Information.

\section{Discussion}

The present findings allow a clear attribution of the $(\sqrt{3} \times \sqrt{3})-\alpha$ and $(\sqrt{3} \times \sqrt{3})-\beta$ phases. There are already several experimental evidences that the $(\sqrt{3} \times \sqrt{3})-\beta$ phase consists of both $\mathrm{Ag}$ and $\mathrm{Si}$ atoms lying on a silicon layer in a structure analogous to the $(\sqrt{3} \times \sqrt{3})$ reconstruction observed on $\mathrm{Ag} / \mathrm{Si}(111) .^{44,45,50-52}$ This corresponds to the present $\mathrm{ML}+\mathrm{Si} / \mathrm{Ag}$ and $\mathrm{BL}+\mathrm{Si} / \mathrm{Ag}$ structures and, indeed, the

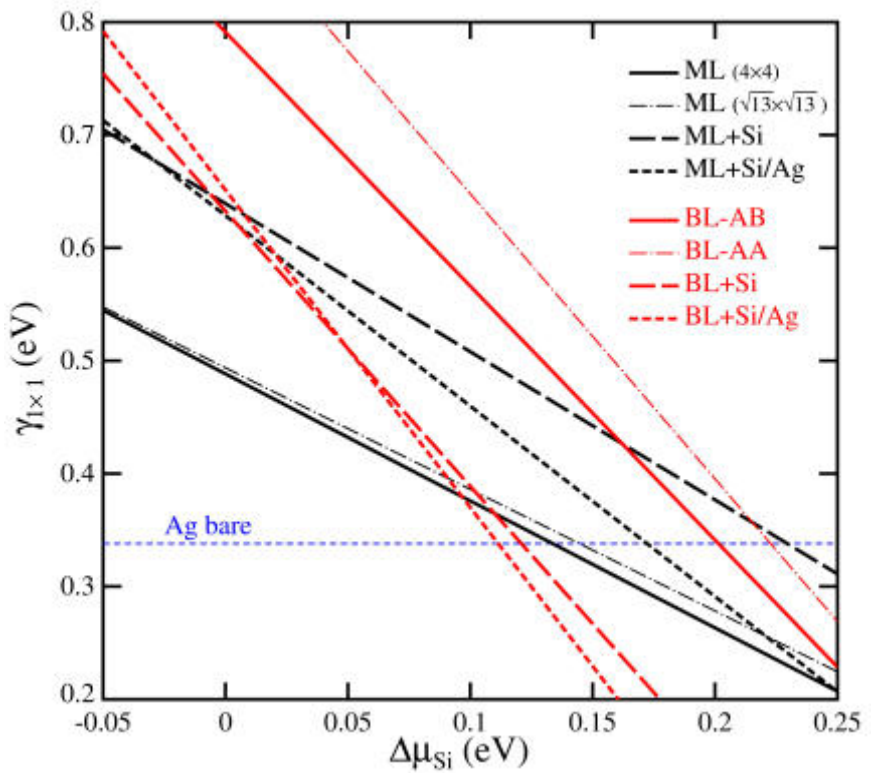

Figure 7: Surface energies of the different phases as a function of the Si chemical potential. $\gamma_{1 \times 1}=\gamma \times A_{1 \times 1}$ where $\gamma$ is defined in Equation 1 and $A_{1 \times 1}$ is the area of the $\mathrm{Ag}(111)$ surface unit-cell. The silicene monolayer $(\mathrm{ML})$ is calculated in the two $(4 \times 4)$ and $(\sqrt{13} \times \sqrt{13})$ reconstructions. "Ag bare" corresponds to the relaxed $\mathrm{Ag}(111)$ surface. Other labels are defined in the text.

corresponding simulated STM images (Figure 6) display intrusions with $(\sqrt{3} \times \sqrt{3})$ periodicity as those experimentally observed for the $(\sqrt{3} \times \sqrt{3})-\beta$ (Figure 2). Note that the simulated STM images of the $\mathrm{ML}+\mathrm{Si} / \mathrm{Ag}$ and $\mathrm{BL}+\mathrm{Si} / \mathrm{Ag}$ structures are quite different from those of the $(\sqrt{3} \times \sqrt{3})$ $\mathrm{Ag} / \mathrm{Si}(111)$ reported in literature, ${ }^{62}$ despite the fact that the atomic structures of the three systems are very similar. This issue is discussed in the Supporting Information.

Concerning the $\alpha$ phase, the present STM measurements reveal that it is a structure clearly distinct from the $\beta$ one

(Figure 2). Assuming thus that the $(\sqrt{3} \times \sqrt{3})-\alpha$ is an Ag-free structure, we can compare it to the BL-AB, BL-AA, ML+Si, BL+Si structures. The BL-AB and BL-AA ones are unlikely to correspond to the $\alpha$ phase: according to our calculation (which confirms what already remarked in ref. 38) the BL-AB structure does not reconstruct with the $(\sqrt{3} \times \sqrt{3})$ periodicity of the $\alpha$ phase, and the BL-AA structure (which actually presents the $(\sqrt{3} \times \sqrt{3})$ reconstruction) has a very high energy, compared with the one of the bilayer (BL-AB, Figure 7), probably because of the AA stacking. On the other hand, both $\mathrm{ML}+\mathrm{Si}$ and $\mathrm{BL}+\mathrm{Si}$ are good candidates for the $\alpha$ phase: they are significantly more stable than the BL-AB structure (Figure 7) and reconstruct with $(\sqrt{3} \times \sqrt{3})$ periodicity, displaying STM images which nicely resemble those of the $\alpha$ phase (Figure 6). In the previous two paragraphs, we concluded that the $\alpha$ phase corresponds to either $\mathrm{ML}+\mathrm{Si}$ or $\mathrm{BL}+\mathrm{Si}$ structures, and that the $\beta$ phase corresponds to either $\mathrm{ML}+\mathrm{Si} / \mathrm{Ag}$ or $\mathrm{BL}+\mathrm{Si} / \mathrm{Ag}$ 
ones. We now consider the energetics reported in Figure 7. Keeping in mind that we are not at thermodynamical equilibrium, we argue that a reasonable $\Delta \mu_{\mathrm{Si}}$ range to describe the present experimental conditions is $0<\Delta \mu_{\mathrm{Si}} \lesssim 0.13 \mathrm{eV}$. Indeed, we expect silicene to be metastable with respect to the formation of silicon bulk since, for deposition at $600 \mathrm{~K}$, the silicene layer dewets to form large Si bulk islands. $\Delta \mu_{\mathrm{Si}}=0.13 \mathrm{eV}$ corresponds to the point where the surface becomes fully covered with silicene. When the $\alpha$ islands start to grow, the monolayer is nearly (but not entirely) complete and the chemical potential must thus be close to the value $\Delta \mu_{\mathrm{Si}}=0.13 \mathrm{eV}$.

We remark that, in a large range around $\Delta \mu_{\mathrm{Si}}=0.13 \mathrm{eV}$, the $\mathrm{ML}+\mathrm{Si}$ and $\mathrm{ML}+\mathrm{Si} / \mathrm{Ag}$ structures are less stable than the monolayer (ML). On the other hand, the $\mathrm{BL}+\mathrm{Si}$ and $\mathrm{BL}+\mathrm{Si} / \mathrm{Ag}$ ones are more stable than the clean silicon bilayer (BL-AB). As a consequence, the $\mathrm{ML}+\mathrm{Si}$ and $\mathrm{ML}+\mathrm{Si} / \mathrm{Ag}$ terminations are not expected to form in the presence of the monolayer. On the contrary, the $\mathrm{BL}+\mathrm{Si}$ and $\mathrm{BL}+\mathrm{Si} / \mathrm{Ag}$ ones should form when the second silicene layer starts to grow. The fact that the $\mathrm{ML}+\mathrm{Si}$ and $\mathrm{ML}+\mathrm{Si} / \mathrm{Ag}$ terminations are less stable than the monolayer, while $\mathrm{BL}+\mathrm{Si}$ and $\mathrm{BL}+\mathrm{Si} / \mathrm{Ag}$ are more stable than the bilayer is not entirely surprising. Indeed, while silicene (ML) is a relatively stable configuration with an hybridation different from that of diamond, the bilayer (BL) is more similar to diamond and needs to be stabilized by non-ideal reconstructions as it is the case for bulk-silicon surfaces. As a consequence, the $\alpha$ and $\beta$ phases are attributed to the $\mathrm{BL}+\mathrm{Si}$ and $\mathrm{BL}+\mathrm{Si} / \mathrm{Ag}$ structures, respectively.

One of the most interesting observation, among the present ones, is that the formation of the $(\sqrt{3} \times \sqrt{3})-\beta$ phase is accompanied by an increase in height of the adjacent silicene regions, which testifies the intercalation of $\mathrm{Ag}$ atoms under these monolayers (Figures 3-5). The emergence of these additional $\mathrm{Ag}$ atoms is, at first sight, very puzzling and raises the question of their origin. Knowing that the $\beta$ phase is a

bilayer $(\mathrm{BL}+\mathrm{Si} / \mathrm{Ag})$, the most natural answer is that the bottom Si-layer of the bilayer is located below the original silicene monolayer and forms by dislodging the atoms of the outermost Ag layer (Figure 1). The expulsed Ag atoms partially intercalate under neighboring silicene regions, increasing the height of the terraces, and partially go on the top of silicon (to form the $(\sqrt{3} \times \sqrt{3})-\beta$ reconstruction). We argue that this dynamics has already started during the formation of the $(\sqrt{3} \times \sqrt{3})-\alpha$ phase. This is not evident on the sole basis of Figures 3-5. However, we have already concluded that the $\alpha$ phase is a bilayer $(\mathrm{BL}+\mathrm{Si})$. If we also consider that the measured STM height of the $\alpha$ phase is smaller than that of the $\beta$ one ( 0.21 vs. $0.30 \mathrm{~nm}$ ) we can deduce that the $\mathrm{BL}+\mathrm{Si}$ structure has also formed by expelling the outermost Ag layer (otherwise the height would be much higher). Note also that the attribution of $(\sqrt{3} \times \sqrt{3})-\alpha$ and $(\sqrt{3} \times \sqrt{3})-\beta$ to bilayers $(\mathrm{BL}+\mathrm{Si}$ and $\mathrm{BL}+\mathrm{Si} / \mathrm{Ag})$ that are inserted below the outermost $\mathrm{Ag}$ layer is compatible with the calculated STM heights reported in Table I.

The presently described dynamics is compatible with the energetics for the adsorption of one $\mathrm{Si}$ atom on silicene/Ag(111). According to the calculations described in the Supporting Information, the substitution of a Si atom with one $\mathrm{Ag}$ atom of the outermost $\mathrm{Ag}$ layer (which is below the silicene) is energetically favoured with respect to the adsorption of one Si atom on the top of silicene. This dynamics contrasts with a more intuitive and classical picture in which a $\mathrm{Si}$ atom would stick on the top of the surface and act as a nucleation centre for the growth of the second layer. Exchange between $\mathrm{Si}$ and $\mathrm{Ag}$ atoms already occur in the initial stage of growth: the insertion of a $\mathrm{Si}$ atom within the clean $\mathrm{Ag}(111)$ surface is a relatively fast process associated with an experimentally-determined small energy barrier of $0.43 \mathrm{eV} .^{56}$ However, it is safe to assume that the insertion of a $\mathrm{Si}$ atom below an existing silicene layer should be associated with a high activation barrier. Thus, if we also assume fast diffusion of the $\mathrm{Si}$ atoms adsorbed on the silicene layer, the adsorbed $\mathrm{Si}$ atoms should be allowed to reach a particularly favoured location (possibly a step or a defect) to insert below the silicene layer. This picture could explain why the bilayer starts growing only when the monolayer has completely covered the Ag surface, a fact observed experimentally.

Indications that the Si adatom diffusion is fast are given by DFT calculations on free-standing silicene, ${ }^{63}$ which provide an energy barrier of $0.75 \mathrm{eV}$ for the diffusion of a dumbbell unit created by addition of a $\mathrm{Si}$ adatom. This should result in a high jump rate at $T=500 \mathrm{~K}$, of the order of $10^{5} \mathrm{~s}^{-1}$, considering a usual attempt frequency of $10^{13} \mathrm{~s}^{-1}$. Note also that the reorganization of the silicene layer during growth (which involves $\mathrm{Si}-\mathrm{Si}$ bond breaking) has been predicted ${ }^{64}$ and experimentally observed. ${ }^{56}$ Thus, energy barriers for Si diffusion and $\mathrm{Si}-\mathrm{Si}$ bond reorganization are low enough to enable 2D growth at $500 \mathrm{~K}$.

Concerning the $\mathrm{Ag}$ kinetics, the expelled $\mathrm{Ag}$ atoms are expected to easily wet $\mathrm{Si}$ islands due to their fast diffusion. Indeed, an activation barrier of $0.25 \mathrm{eV}$ has been measured for $\mathrm{Ag}$ atoms on the $\mathrm{Si}(111)(7 \times 7)$ surface. ${ }^{65}$ The diffusion of $\mathrm{Ag}$ atoms on the $\mathrm{Ag}$ induced $(\sqrt{3} \times \sqrt{3})$ reconstruction of $\mathrm{Si}$ is also fast, with a barrier of $0.33 \mathrm{eV} .^{66}$ Lower barriers should be obtained for $\mathrm{Ag}$ atomic jumps on the silicene surface, in analogy with graphene. Finally, further growth of the $\mathrm{Si}$ islands proceeds by exchange between incoming $\mathrm{Si}$ atoms and surface Ag atoms forming the $(\sqrt{3} \times \sqrt{3})$ reconstruction. Such effect has been already evidenced during Si homoepitaxy on Si(111)$(\sqrt{3} \times \sqrt{3}) \mathrm{Ag}$ at $570 \mathrm{~K} .^{67}$ Silicon diffusion through the $\mathrm{Ag}$ layer has also been evidenced during Co deposition on $\mathrm{Si}(111)$ $(\sqrt{3} \times \sqrt{3})$ Ag where cobalt silicide formation on the $(\sqrt{3} \times \sqrt{3})$ reconstruction is observed above $400 \mathrm{~K}^{68}$ 


\section{Methods}

\section{Sample preparation and Si evaporation}

All experiments were performed in set-ups working under ultra-high vacuum (base pressure $10^{-10}$ mbar). The $\mathrm{Ag}(111)$ sample was prepared by repeated cycles of $\mathrm{Ar}^{+}$sputtering and annealing at $800 \mathrm{~K}$. Si was evaporated from a thermally heated crucible using a commercial Omicron Nanotechnology e-beam evaporator. The evaporation rate was around $0.004 \mathrm{ML} / \mathrm{min}$.

\section{STM experiments}

STM experiments were carried out using an Omicron Nanotechnology VT STM. STM images were directly acquired during $\mathrm{Si}$ evaporation. In order to avoid a continuous shadowing of the surface by the STM tip, various areas were scanned successively. Temperature measurement is performed with a thermocouple located on the sample heating stage, previously calibrated with another thermocouple soldered on the surface of a testing sample. The uncertainty on the absolute value of the temperature is around 10 to $20 \mathrm{~K}$ at $500 \mathrm{~K}$.

\section{DFT calculations}

We used the Quantum ESPRESSO package, ${ }^{69}$ and the projector augmented plane wave method of ref. 70. The energy cut-off of plane waves was 30 Ry and that of the charge 240 Ry. The $\mathrm{Ag}$ (111) surface is described by a four layers slab. Atomic positions were always relaxed by energy minimization (only the Ag-slab bottom-layer positions were fixed) fixing the inplane lattice spacing to the theoretical Ag bulk one $(0.2935$ $\mathrm{nm})$. The Brillouin zone of the $(4 \times 4) \mathrm{Ag}(111)$ super-cell was sampled with $6 \times 6 \times 1 k$ points and a Gaussian smearing of 0.025 Ry. STM simulations ${ }^{71}$ were done by determining, first, the local density of states at $U$ above the Fermi energy and, then, the height of the surface at constant density. Results were systematically tested against the inclusion of dipole corrections. $^{72}$

\section{Conclusions}

To conclude, we have studied silicene growth dynamics (beyond the monolayer) on the $\mathrm{Ag}(111)$ surface by means of real-time in-situ STM measurements and DFT calculations, providing a consistent scenario explaining all the experimental and numerical observations. The silicene monolayer is a relatively stable structure with respect to atom addition, always maintaining its honeycomb structure. The $(\sqrt{3} \times \sqrt{3})-\alpha$ and $(\sqrt{3} \times \sqrt{3})-\beta$ reconstructions observed experimentally are non-ideal terminations of silicon bilayers. The bilayers form by expelling the underneath atoms of the outermost Ag layer. An ideal bilayer, i.e. a stacking of two silicene planes, is never observed and the thicker layers are stabilized in two alternative ways. In the early stages of the growth, a Ag-free structure ( $\alpha$ phase) bearing analogies with that of the $(7 \times 7)$ reconstruction of the bulk $\mathrm{Si}(111)$ surface can be observed. After this initial stage, the bilayer is stabilized in a structure covered by Si trimers and $\mathrm{Ag}$ atoms ( $\beta$ phase), analogous to the structure of the $\mathrm{Ag} / \mathrm{Si}(111)(\sqrt{3} \times \sqrt{3})$ reconstruction. The next stages of the growth follow a standard layer-by-layer growth, in which the outermost Si-Ag structure does not change. During this growth, the silicon interlayer distance is very similar to that of the diamond structure, making hard to probe the existence of a "multilayer silicene" structure bearing distinct properties from those of a diamond with an important stacking disorder. The present scenario indicates a surfactant competition between Si and Ag, driven by the high kinetic barrier to transform a silicene monolayer into thick $\mathrm{Si}$ islands. While silicene is a metastable surfactant for the $\mathrm{Ag}(111)$ surface, $\mathrm{Ag}$ plays the role of a surfactant for diamond-like $\mathrm{Si}$ islands. If we now consider the experimental results discussed in the introduction: for temperatures below $540 \mathrm{~K}$, the atomic mobility is low enough to inhibit the complete dewetting of the silicene layer. Above $540 \mathrm{~K}, \mathrm{Si}$ thick islands act as nucleation centers for the dewetting of silicene, leading to thick 3D islands separated by bare Ag regions. ${ }^{21}$

\section{Conflicts of interest}

There are no conflicts to declare.

\section{Acknowledgements}

This work was supported by French state funds managed by the ANR within the Investissements d'Avenir programme under reference ANR-11-IDEX-0004-02, and more specifically within the framework of the Cluster of Excellence MATISSE led by Sorbonne Universités.

\section{Notes and references}

1 A. K. Geim and I. V. Grigorieva, Nature, 2013, 499, 419-425.

2 S. Z. Butler, S. M. Hollen, L. Cao, Y. Cui, J. A. Gupta, H. R. Gutiérrez, T. F. Heinz, S. S. Hong, J. Huang, A. F. Ismach, E. Johnston-Halperin, M. Kuno, V. V. Plashnitsa, R. D. Robinson, R. S. Ruoff, S. Salahuddin, J. Shan, L. Shi, M. G. Spencer, M. Terrones, W. Windl and J. E. Goldberger, ACS Nano, 2013, 7, 2898-2926.

3 K. Takeda and K. Shiraishi, Phys. Rev. B, 1994, 50, 14916.

4 G. Guzmán-Verri and L. Lew Yan Voon, Phys. Rev. B, 2007, 76, 075131.

5 S. Cahangirov, M. Topsakal, E. Aktürk, H. Şahin and S. Ciraci, Phys. Rev. Lett., 2009, 102, 236804.

6 A. Kara, H. Enriquez, A. P. Seitsonen, L. C. L. Y. Voon, S. Vizzini, B. Aufray and H. Oughaddou, Surf. Sci. Rep., 2012, 67, 1-18.

7 K.-H. Wu, Chin. Phys. B, 2015, 24, 086802.

8 Y. Yamada-Takamura and R. Friedlein, Sci. Technol. Adv. Mater., 2014, 15, 064404.

9 J. Zhao, H. Liu, Z. Yu, R. Quhe, S. Zhou, Y. Wang, C. C. Liu, H. Zhong, N. Han, J. Lu, Y. Yao and K. Wu, Prog. Mater. Sci., 2016, 83, 24-151. 
10 H. Oughaddou, H. Enriquez, M. R. Tchalala, H. Yildirim, A. J. Mayne, A. Bendounan, G. Dujardin, M. Ait Ali and A. Kara, Prog. Surf. Sci., 2015, 90, 46-83.

11 M. Houssa, A. Dimoulas and A. Molle, J. Phys. Condens. Matter, 2015, 27, 253002.

12 C. Léandri, H. Oughaddou, B. Aufray, J. M. Gay, G. Le Lay, A. Ranguis and Y. Garreau, Surf. Sci., 2007, 601, 262-267.

13 C. Leandri, G. L. Lay, B. Aufray, C. Girardeaux, J. Avila, M. E. Dávila, M. C. Asensio, C. Ottaviani and A. Cricenti, Surf. Sci., 2005, 574, L9-L15.

14 J. I. Cerdá, J. Sławińska, G. Le Lay, A. C. Marele, J. M. Gómez-Rodríguez and M. E. Dávila, Nat. Commun., 2016, 7, 13076.

15 G. Prévot, C. Hogan, T. Leoni, R. Bernard, E. Moyen and L. Masson, Phys. Rev. Lett., 2016, 117, 276102.

16 P. Vogt, P. De Padova, C. Quaresima, J. Avila, E. Frantzeskakis, M. C. Asensio, A. Resta, B. Ealet and G. Le Lay, Phys. Rev. Lett., 2012, 108, 155501.

$17 \mathrm{H}$. Jamgotchian, Y. Colignon, B. Ealet, B. Parditka, J.-Y. Hoarau, C. Girardeaux, B. Aufray and J.-P. Bibérian, J. Phys. Conf. Ser., 2014, 491, 012001.

18 P. Moras, T. O. Mentes, P. M. Sheverdyaeva, A. Locatelli and C Carbone, J. Phys. Condens. Matter, 2014, 26, 185001.

19 C. Grazianetti, D. Chiappe, E. Cinquanta, M. Fanciulli and A. Molle, J. Phys. Condens. Matter, 2015, 27, 255005.

20 A. Curcella, R. Bernard, Y. Borensztein, A. Resta, M. Lazzeri and G. Prévot, Phys. Rev. B, 2016, 94, 165438.

21 A. Acun, B. Poelsema, H. J. W. Zandvliet and R. van Gastel, Appl. Phys. Lett., 2013, 103, 263119.

22 B. Feng, Z. Ding, S. Meng, Y. Yao, X. He, P. Cheng, L. Chen and K. Wu, Nano Lett., 2012, 12, 3507-3511.

23 P. De Padova, P. Vogt, A. Resta, J. Avila, I. Razado-Colambo, C. Quaresima, C. Ottaviani, B. Olivieri, T. Bruhn, T. Hirahara, T. Shirai, S. Hasegawa, M. Carmen Asensio and G. Le Lay, Appl. Phys. Lett., 2013, 102, 163106.

24 P. De Padova, J. Avila, A. Resta, I. Razado-Colambo, C. Quaresima, C. Ottaviani, B. Olivieri, T. Bruhn, P. Vogt, M. C. Asensio and G. Le Lay, J. Phys.-Condens. Matter, 2013, 25, 382202.

25 P. Vogt, P. Capiod, M. Berthe, A. Resta, P. De Padova, T. Bruhn, G. Le Lay and B. Grandidier, Appl. Phys. Lett., 2014, 104, 021602.

26 J. Sone, T. Yamagami, Y. Aoki, K. Nakatsuji and H. Hirayama, New J. Phys., 2014, 16, 095004.

27 E. Salomon, R. E. Ajjouri, G. L. Lay and T. Angot, J. Phys. Condens. Matter, 2014, 26, 185003.

28 P. De Padova, C. Quaresima, C. Ottaviani, P. M. Sheverdyaeva, P. Moras, C. Carbone, D. Topwal, B. Olivieri, A. Kara, H. Oughaddou, B. Aufray and G. Le Lay, Appl. Phys. Lett., 2010, 96, 261905.

29 P. De Padova, C. Ottaviani, C. Quaresima, B. Olivieri, P. Imperatori, E. Salomon, T. Angot, L. Quagliano, C. Romano, A. Vona, M. Muniz-Miranda, A. Generosi, B. Paci and G. Le Lay, 2D Mater., 2014, 1, 021003.

30 P. De Padova, A. Generosi, B. Paci, C. Ottaviani, C. Quaresima, B. Olivieri, E. Salomon, T. Angot and G. Le Lay, 2D Mater., 2016, 3, 031011.
31 C. Grazianetti, E. Cinquanta, L. Tao, P. De Padova, C. Quaresima, C. Ottaviani, D. Akinwande and A. Molle, ACS Nano, 2017, 11, 3376-3382.

32 Y. Wang, K. Scheerschmidt and U. Gösele, Phys. Rev. B, 2000, 61, 12864.

33 S. Cahangirov, V. O. Özçelik, A. Rubio and S. Ciraci, Phys. Rev. B, 2014, 90, 085426.

34 S. Cahangirov, V. O. Özçelik, L. Xian, J. Avila, S. Cho, M. C. Asensio, S. Ciraci and A. Rubio, Phys. Rev. B, 2014, 90, 035448.

35 L. Chen, C.-C. Liu, B. Feng, X. He, P. Cheng, Z. Ding, S. Meng, Y. Yao and K. Wu, Phys. Rev. Lett., 2012, 109, 056804.

36 L. Chen, H. Li, B. Feng, Z. Ding, J. Qiu, P. Cheng, K. Wu and S. Meng, Phys. Rev. Lett., 2013, 110, 085504.

37 Y. Sakai and A. Oshiyama, Phys. Rev. B, 2015, 91, 201405.

38 P. Pflugradt, L. Matthes and F. Bechstedt, Phys. Rev. B, 2014, 89, 205428.

39 M. Ezawa, J. Phys. Soc. Jpn., 2012, 81, 104713.

40 N. W. Johnson, D. Muir, E. Z. Kurmaev and A. Moewes, Adv. Funct. Mater., 2015, 25, 4083-4090.

41 T. Shirai, T. Shirasawa, T. Hirahara, N. Fukui, T. Takahashi and S. Hasegawa, Phys. Rev. B, 2014, 89, 241403.

42 A. J. Mannix, B. Kiraly, B. L. Fisher, M. C. Hersam and N. P. Guisinger, ACS Nano, 2014, 8, 7538-7547.

43 Y. Borensztein, A. Curcella, S. Royer and G. Prévot, Phys. Rev. B, 2015, 92, 155407.

44 A. Curcella, Y. Borensztein, R. Bernard, M. Lazzeri, A. Resta, Y. Garreau and G. Prévot, 2D Mater., 2017, 4, 025067.

45 K. Kawahara, T. Shirasawa, C.-L. Lin, R. Nagao, N. Tsukahara, T. Takahashi, R. Arafune, M. Kawai and N. Takagi, Surf. Sci., 2016, 651, 70-75.

46 H. Fu, L. Chen, J. Chen, J. Qiu, Z. Ding, J. Zhang, K. Wu, H. Li and S. Meng, Nanoscale, 2015, 7, 15880-15885.

47 J. Chen, Y. Du, Z. Li, W. Li, B. Feng, J. Qiu, P. Cheng, S. Xue Dou, L. Chen and K. Wu, Sci. Rep., 2015, 5, 13590.

48 Z.-X. Guo and A. Oshiyama, Phys. Rev. B, 2014, 89, 155418.

49 Z.-X. Guo and A. Oshiyama, New J. Phys., 2015, 17, 045028.

50 G.-W. Lee, H.-D. Chen and D.-S. Lin, Appl. Surf. Sci., 2015, 354, 212-215.

51 S. K. Mahatha, P. Moras, P. M. Sheverdyaeva, R. Flammini, K. Horn and C. Carbone, Phys. Rev. B, 2015, 92, 245127.

52 H.-D. Chen, K.-H. Chien, C.-Y. Lin, T.-C. Chiang and D.-S. Lin, J. Phys. Chem. C, 2016, 120, 2698-2702.

53 H. Tajiri, K. Sumitani, S. Nakatani, A. Nojima, T. Takahashi, K. Akimoto, H. Sugiyama, X. Zhang and H. Kawata, Phys. Rev. B, 2003, 68, 035330.

54 T. Takahashi and S. Nakatani, Surf. Sci., 1993, 282, 17-32.

55 G. Prévot, R. Bernard, H. Cruguel and Y. Borensztein, Appl. Phys. Lett., 2014, 105, 213106.

56 R. Bernard, Y. Borensztein, H. Cruguel, M. Lazzeri and G. Prévot, Phys. Rev. B, 2015, 92, 045415.

57 M. Satta, S. Colonna, R. Flammini, A. Cricenti and F. Ronci, Phys. Rev. Lett., 2015, 115, 026102.

58 J. P. Perdew, K. Burke and M. Ernzerhof, Phys. Rev. Lett., 1996, 77, 3865-3868.

59 S. Grimme, J. Comput. Chem., 2006, 27, 1787-1799. 
60 V. Barone, M. Casarin, D. Forrer, M. Pavone, M. Sambi and A. Vittadini, J. Comput. Chem., 2009, 30, 934-939.

61 I. Matsuda, H. Morikawa, C. Liu, S. Ohuchi, S. Hasegawa, T. Okuda, T. Kinoshita, C. Ottaviani, A. Cricenti, M. D’angelo, P. Soukiassian and G. Le Lay, Phys. Rev. B, 2003, 68, 085407.

62 H. Aizawa, M. Tsukada, N. Sato and S. Hasegawa, Surf. Sci., 1999, 429, L509-L514.

63 V. O. Özçelik, D. Kecik, E. Durgun and S. Ciraci, J. Phys. Chem. C, 2015, 119, 845-853.

64 M. J. Cherukara, B. Narayanan, H. Chan and S. K. R. S. Sankaranarayanan, Nanoscale, 2017, 9, 10186-10192.

65 D. Wall, I. Lohmar, K. R. Roos, J. Krug, M. Horn-von Hoegen and F.-J. Meyer zu Heringdorf, New J. Phys., 2010, 12, 103019.

66 M. Hanbücken, M. Futamoto and J. A. Venables, Surf. Sci., 1984, 147, 433-450.

67 T. Yamagami, J. Sone, K. Nakatsuji and H. Hirayama, Appl. Phys. Lett., 2014, 105, 151603.

68 C.-H.-T. Chang, T.-Y. Fu and J.-S. Tsay, J. Appl. Phys., 2015, 117, $17 \mathrm{~B} 733$.

69 P. Giannozzi, S. Baroni, N. Bonini, M. Calandra, R. Car, C. Cavazzoni, D. Ceresoli, G. L. Chiarotti, M. Cococcioni, I. Dabo, A. Dal Corso, S. de Gironcoli, S. Fabris, G. Fratesi, R. Gebauer, U. Gerstmann, C. Gougoussis, A. Kokalj, M. Lazzeri, L. Martin-Samos, N. Marzari, F. Mauri, R. Mazzarello, S. Paolini, A. Pasquarello, L. Paulatto, C. Sbraccia, S. Scandolo, G. Sclauzero, A. P. Seitsonen, A. Smogunov, P. Umari and R. M. Wentzcovitch, J. Phys.Condens. Matter, 2009, 21, 395502.

70 G. Kresse and D. Joubert, Phys. Rev. B, 1999, 59, 17581775.

71 J. Tersoff and D. R. Hamann, Phys. Rev. B, 1985, 31, 805813.

72 L. Bengtsson, Phys. Rev. B, 1999, 59, 12301. 